\title{
Experimental Modal Analysis of Stator Overhangs of a Large Turbogenerator
}

\author{
Ram Sewak, Rajesh Ranjan, Vivek Kumar \\ Heavy Electrical Equipment Plant (HEEP), Bharat Heavy Electricals Limited, Haridwar, India \\ E-mail: \{ramsewak, rranjan, vivek\}@bhelhwr.co.in \\ Received March 12, 2011; revised April 10, 2011; accepted May 3, 2011
}

\begin{abstract}
Modal analysis of engineering structure for comprehending/resolving the vibration related issues/problems are well known. Two classical techniques-analytical (Finite Element Method-FEM) and experimental (Impact testing/Natural Frequency Test-NFT/Bump test) are generally used as complementary as well as stand-alone depending on the time, nature of structure, availability of the analysis tools, cost etc. In the present study, experimental technique was used in mitigating the endwinding vibration problem of a turbogenerator. In one of the Turbogenerators of $50 \mathrm{~Hz}$ variant, an increasing vibration trend was observed with system frequency sweep in almost whole of the endwinding basket particularly more on exciter end during sustained short/ open circuit conditional runs. Experimental modal analysis was carried out of the overhangs. Frequency response functions (FRFs) were generated in local and global modes. The analysis thereon indicated global resonance of stator overhangs. Accordingly, appropriate remedial measures were planned and implemented. Consequently, global resonance frequency was shifted to higher zone, which in turn, resulted into substantial reduction in endwinding vibration levels.
\end{abstract}

Keywords: Turbogenerator, Endwinding Vibration

\section{Introduction}

Modal analysis is a well known technique for analysis and resolution of vibration problems of engineering structures. However, this has recently found use in analyzing the turbogenerator stator endwinding vibration. Its principal co-ordinates-natural frequency, damping and associated mode shape are the functions of structure's geometry, mass, stiffness, temperature, and boundary conditions.

Generator stator endwinding is one of the most intensively stressed unit components of a turbogenerator. Endwindings can be excited by electromagnetic forces due to the stator and rotor currents in stationary and transient conditions at simple and double system frequency, core vibrations at double system frequency, unbalances in the rotating shaft at system frequency being transmitted to the endwinding via the housing and core [1].

The present study relates to a Turbogenerator of $50 \mathrm{~Hz}$ variant, where increasing vibration trend of nearly whole endwinding basket was observed during sustained short circuit and open circuit conditional runs, particularly when the system frequency of prime-mover was varied from $47.5 \mathrm{~Hz}$ to $51.5 \mathrm{~Hz}$. The trend was more dominant on Exciter End (EE), compared to Turbine End (TE) (Figures 1 and 2). In view of this, it was decided to carry out investigation of such a vibration behaviour of endwinding structure by experimental modal analysis. This involved:

1) Impact testing of overhang structures on specific points and generation of FRFs in standstill condition in local and global mode;

2) Extraction of modal parameters from FRFs generated-frequency, damping and mode shape;

3) Validating the results during operation of the generator by actually tuning the prime-mover's frequency.

This papers deals with experimental study conducted on overhang structures in a limited frequency span, concept of theoretical deformation shape of 4-node mode/ 2-lobe mode for a two-pole generator, its practical implication on overall vibration behavior of endwinding basket, rectification measures implemented and their effectiveness validated using measured data.

\section{Vibration Monitoring}

Largely, piezoelectric accelerometers were used for endwinding vibration monitoring. However, lately, Fi- 


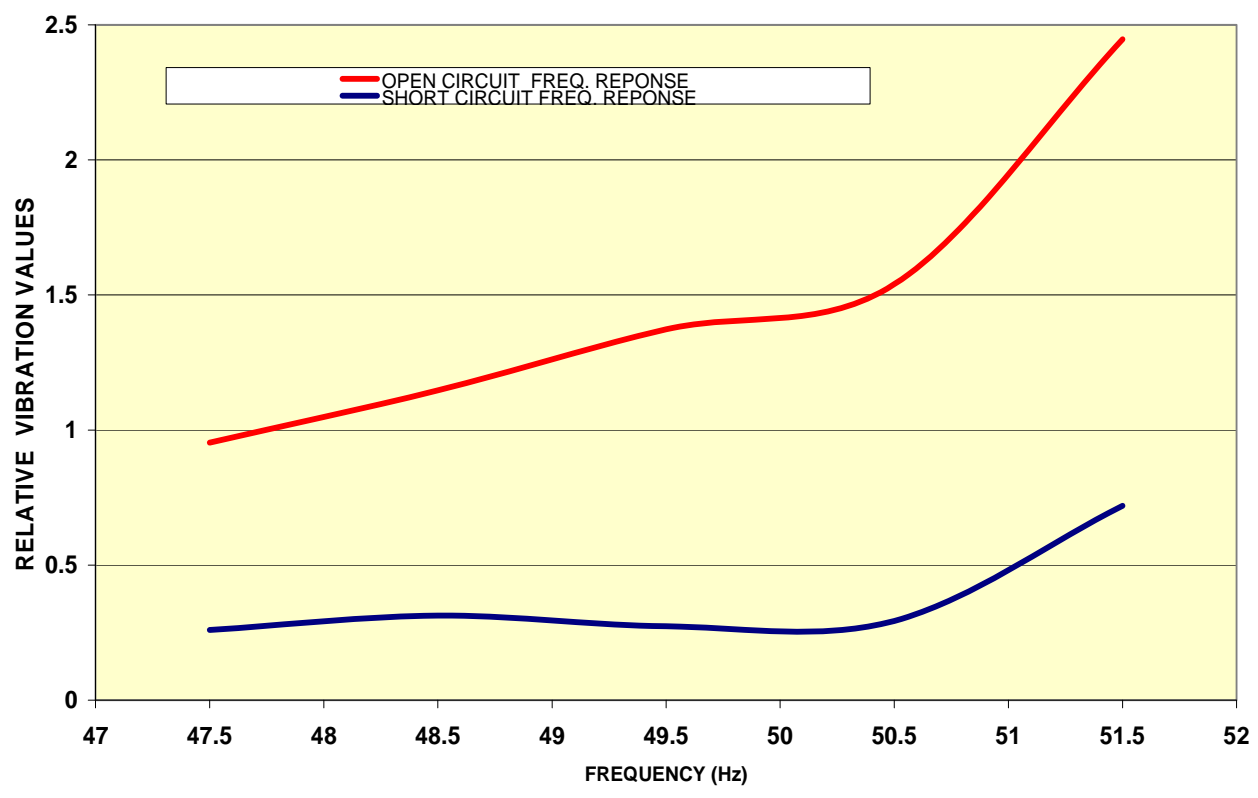

Figure 1. Endwinding vibration behaviour on Exciter End.

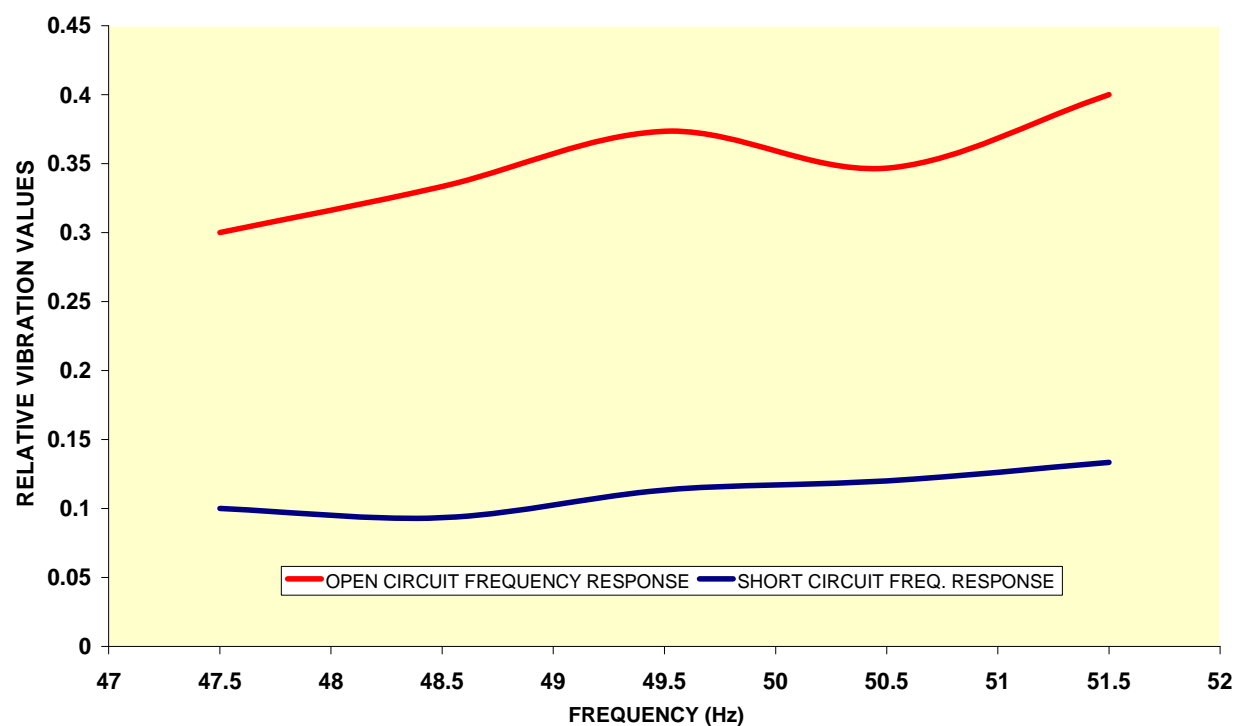

Figure 2. Endwinding vibration behaviour on Turbine End.

bre-Optic Accelerometers (FOA) also have been used particularly on high voltage components like phase bar head-joints, connections etc. For data recording and measurement, stand-alone continuous on-line monitoring system was used.

Generally, three neutral/near neutral points of generator stator endwinding bar head-joints are chosen on each side of TE and EE for mounting six piezo-electric accelerometers in radial and tangential/circumferential directions. Two probes-in radial and tangential directions are screwed on to a single patented epoxy insulated baseplate which in turn, is glued to bar head-joint with putty.
The probe-cables are taken out over the involute overhang from inside of the generator casing to a monitoring instrumentation set-up via specially designed lead-inplates [5].

The generator was operated on no-load i.e. sustained short circuit condition (SCC) at rated $\boldsymbol{I}_{n}$ and open circuit condition (OCC) at rated $\boldsymbol{V}_{n}$. Vibration measurements were carried out on the above conditions for all the 12-points simultaneously. The average winding temperature in SCC was about $60^{\circ} \mathrm{C}$ while in OCC, it was about $45^{\circ} \mathrm{C}$. Also, vibrations were recorded continuously during system frequency sweep of prime-mover from 
47.5 Hz to $51.5 \mathrm{~Hz}$ (Figures 1 and 2).

The stator endwindings are subjected to three different vibratory forces [2].

1) Pulsating forces during start-up, shutdown and normal operation due to forced vibration

- of the entire end-winding system, induced by bearing and stator frame vibrations (excitation frequency depending on the rotor speeds)

- of the entire end-winding system induced by core vibrations (double frequency excitation)

- of each single bar, induced by electromagnetic forces (double-frequency excitation);

2) Forces resulting from restrained thermal expansion which depends upon generator load and coolant temperature;

3) Electromagnetic forces of double system frequency resulting from a high D.C. component arising from abnormal operating conditions especially during short circuit conditions during synchronization.

Resulting endwinding vibration, largely, is a combination of electromagnetic vibrations of windings (self excited vibration) and core induced magnetic vibration which is independent to stator current.

\section{Modal Analysis}

Modes of vibration are inherent properties of a structure. These are determined by the material properties (mass, stiffness and damping), geometric configuration, and boundary conditions of the structure. Each mode is defined by a natural (modal or resonant) frequency, modal damping, and a mode shape. If either the material properties or the boundary conditions of a structure change, its modes will change. At or near the natural frequency of a mode, the overall vibration shape of a machine or structure will tend to be dominated by the mode shape of the resonance.

There are two methods for the excitation of the structure:

1) Impact method where sudden stimulus is given to the structure and corresponding response is recorded as a ratio of output and input signals-called FRF (frequency response function);

2) Harmonic excitation by a shaker.

Both approaches have advantages and disadvantages, while the former is quick, less expensive and easy to operate. Impact testing was used in our present study.

\subsection{Impact/Bump Test}

Frequency Response Functions (FRFs) were generated using light /heavy-duty impact hammers B \& K type 8201 and 2304, an ICP accelerometer and a 2-Ch. OROS
34 FFT Analyzer. This test was done on complete wound stator overhang on both the ends-TE/EE in local and global mode.

\subsubsection{Local Mode}

This test determines individual bar head-joint vibration modes. There were 54 bar-head joints. Each bar-head joint was impacted by a light instrumentation hammer in radial and tangential directions separately and corresponding directional responses was recorded as FRFs one at a time in a limited frequency range of $0-200 \mathrm{~Hz}$. This was done on both the ends-TE and EE.

\subsubsection{Global Mode}

This test determines the vibration modes of entire overhang structure. Entire involute overhang of 54 bar-head joints was radially divided into 18-points. One bar head-joint was taken as a reference point. The impact was given on steel bracket near to this point. The probe was mounted on nose joint in radial direction. Frequency Response Functions (FRFs) were recorded by impacting the structure on single reference point and corresponding responses in radial direction was recorded as FRF on designated locations one by one. Thus, measurements on all the 18-points were carried out on both the TE and EE.

\subsection{Modal Parameter Extraction}

The natural frequency and associated mode shape were extracted manually from individual FRF both for local and global mode of measurements. Typical global natural frequencies in a span of $200 \mathrm{~Hz}$ are summarized below:

In local mode, the frequency distribution amongst 54 bar-head joints was quite varied given the fact that individual bar head-joint had different local tightness and other boundary conditions. In global mode, the said variation was very little between point to point as brought out in Figure 3.

The mode shapes were generated semi-manually using recorded FRFs in a MS Excel sheet for all the global natural frequencies of EE. One such mode shape at 110 $\mathrm{Hz}$ is shown in Figure 4. From this, it is clear that the shape is of 4-Node/2-lobe-mode.

\subsection{4-Node/2-Lobe Mode of Overhang}

The electro-magnetic forces in the electrical machines (generator and motors) are of special significance. These have been explained with the help of example of a two-pole motor. In case of higher number of poles only the complexity of form is raised, without producing basically any effects. 


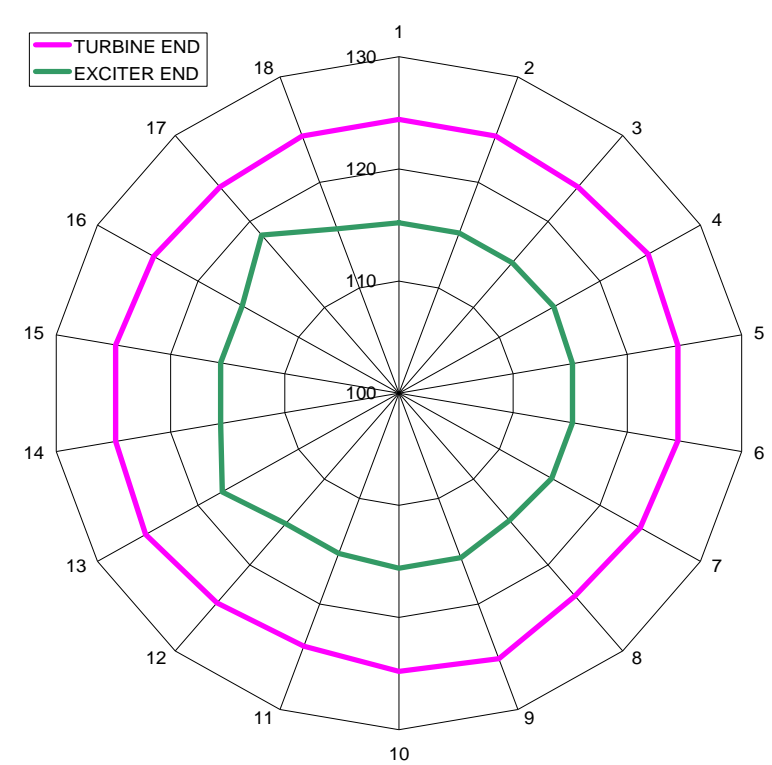

Figure 3. Global natural frequency distribution on overhangs at TE \& EE.

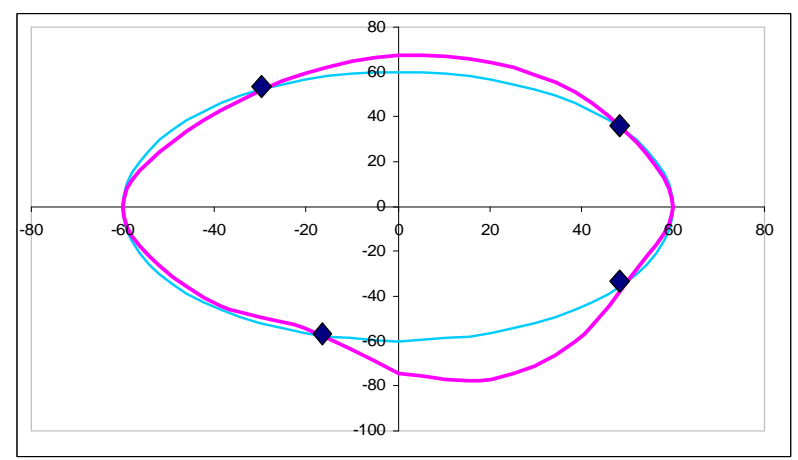

Figure 4. Experimentally generated 4-node/2-lobe deformation of an overhang of a turbogenerator.

Figure 5 points out the magnetic forces with which the pole of the rotor acts on the stator core packet and deforms it to an oval form. The original circular form is superimposed with 4-node points (with red) - where no exact deformation take place. These forces occur as soon as the rotor is excited, that is even in no-load. When the rotor rotates, then the ovality also follows it and stimulates a vibration with the double the rotation frequency $[3,4]$.

Figure 6 describes the front view of an overhang. The plotted current distribution corresponds to the operation with power factor 1 , pure active power. Current exit in upper region of winding from the active part of the stator and accordingly again enters in the lower part. Bar involutes transport the current from the top to bottom half (black arrows). The opposite axial components of current tend to collide with each other, while tangential components exercise the attracting forces (green arrows). They

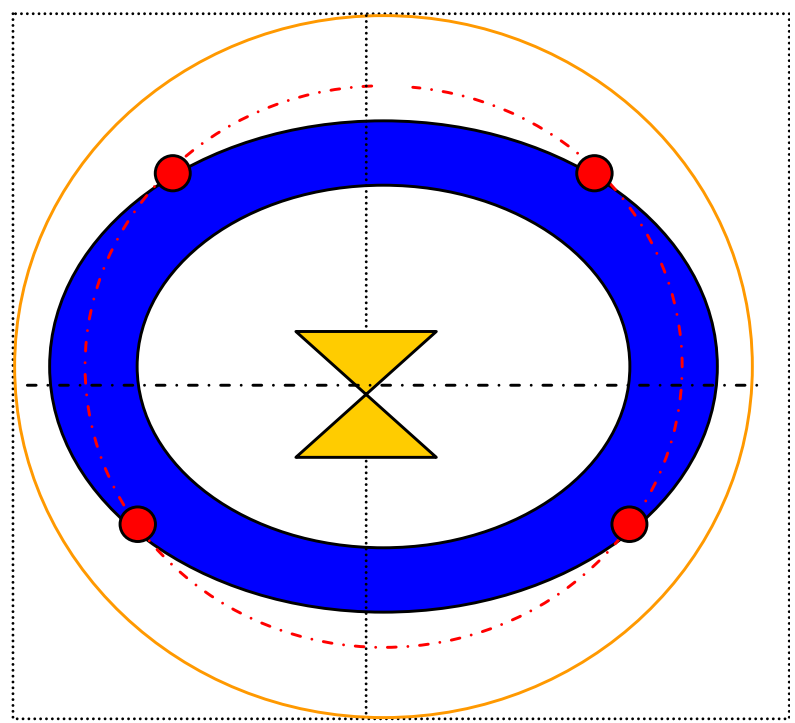

Figure 5. Magnetic forces of rotor.

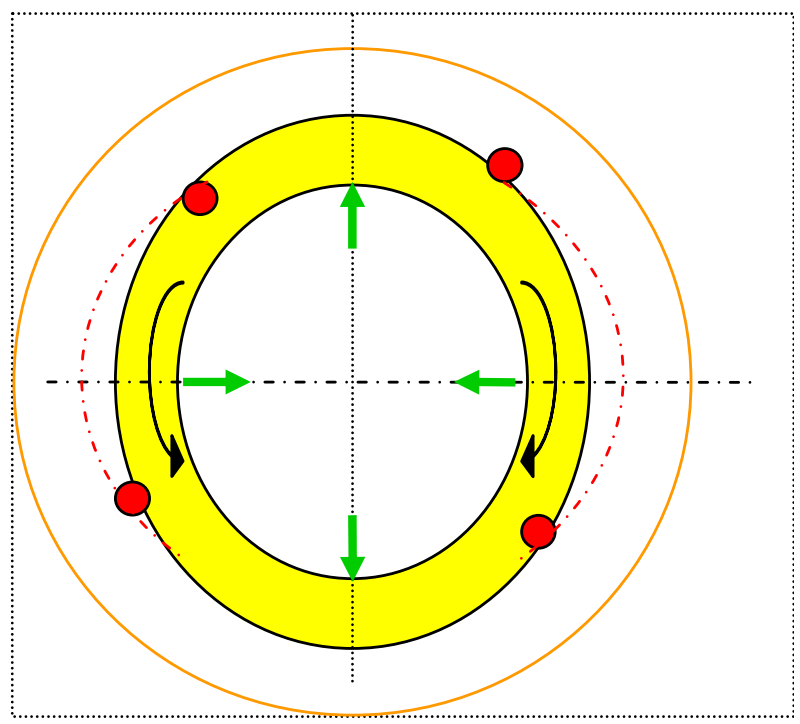

Figure 6. Current forces within the core packet \& overhang.

together make the overhang oval again. It may be noted that the deformation takes place exactly opposite to the deformation in core packet. If additional reactive power is driven and the power factor COSØ becomes less than 1 , then the oval of overhang deformation rotate by angle Ø till it exactly shows the same direction, just as that of the core packet deformation. Overhang forces are proportional to the square of stator current $[3,4]$.

Both the quantities superimpose the electro-magnetic forces at load during operation. While the forces act at different positions of stator, the result of superimposition strongly depend on the place viewed. In general, it is applicable, that the electromagnetic deformation show doubles the number of nodes, as the no of poles. Fre- 
quency is just the double grid frequency for all number of poles. Experimental mode shape generated from global frequency measurements are shown in Figure 4.

\section{Analysis}

1) Since the generator overhang including core vibrate at double the rotor frequency, the natural frequencies near to the system frequency of 50 or $60 \mathrm{~Hz}$ and twice the value, 100 or $120 \mathrm{~Hz}$, are of special interest [1].

The generator was put on operation in SSC and OCC successively for about 4 to 5 hour in each regime, the average winding temperature recorded to about $60^{\circ} \mathrm{C}$ and $45^{\circ} \mathrm{C}$ respectively. Further, in stabilized conditions, when the drive motor frequency swept slowly from $47.5 \mathrm{~Hz}$ to $51.5 \mathrm{~Hz}$, the vibration level on EE shot up sharply (Figures 1 and 2), particularly from $50 \mathrm{~Hz}$ onwards. This behavior can be explained on the basis of structural dynamics. In standstill condition i.e. at normal temperature condition, global natural frequency was obtained as 110 $\mathrm{Hz}$ (Table 1). As the generator run, the temperature of the overhang raised which brought down the natural frequency in the region of nearly 102 to $103 \mathrm{~Hz}$. Since overhang excites at double the fundamental rotor frequency $(2 \times 50 \mathrm{~Hz}=100 \mathrm{~Hz})$ in a 2-pole machine, thus resonance phenomenon might have been occurred when the prime-mover's frequency was swept from $50 \mathrm{~Hz}$ to $51.5 \mathrm{~Hz}$. The reduction of natural frequency at elevated temperature from normal temperature has been reported by others as well [6].

However, the machine could not be operated beyond $51.5 \mathrm{~Hz}$ due to system's limitations, otherwise exact value of resonance frequency would have been detected. On TE, generally, this phenomenon was not observed probably due to higher global natural frequency (Table 1).

In addition to above, 4-node/2-lobe mode shape (Figure 4) of generator overhang obtained at $110 \mathrm{~Hz}$ by modal analysis might have been coincided with the theoretical mode shape. This further aggravated the vibration behavior of overhang.

2) Role of core vibration was also studied by carrying out impact test on it. Dominant natural frequency was found around $84 \mathrm{~Hz}$ which seemed to be quite safe from the resonance point of view.

So, from the above description, it appeared that the

Table 1. Typical global natural frequencies $(\mathrm{Hz})$ obtained on overhangs.

\begin{tabular}{cccc}
\hline \multicolumn{2}{c}{ Global Mode $(\mathrm{Hz})$} & \multicolumn{2}{c}{ Local Mode $(\mathrm{Hz})$} \\
\hline Turbine End & Exciter End & Turbine End. & Exciter End \\
$119.6,146.6,156.6$ & $\mathbf{1 1 0 , 1 2 2 , 1 3 3}$ & $117,133,146$ & $110,125,148$ \\
\hline
\end{tabular}

global natural frequency and its associated 4-node mode of vibration seemed to be the principal cause for higher endwinding vibration on EE.

\section{Rectifying Measures}

In order to arrest the vibration tend, suitable measures were planned and implemented. These measures provided additional stiffness and overall strength to overhang structure. Some of them are given below:

1) Continuous resin rope was introduced encircling all the bar-head joints in order to integrate the overall overhang basket (Figure 7);

2) Additional bracing was provided, so as to increase the stiffness of overhang within phase and also at phase separation;

3) Concerned process bottlenecks were removed by suitable technological means.

\section{Evaluation of Measures}

Subsequent to rectification and testing, following results were obtained:

- Overall global natural frequency was found to be increased about $5 \mathrm{~Hz}$ on $\mathrm{EE}$ and $10 \mathrm{~Hz}$ on TE from the un- rectified situation;

- Endwinding vibration level was reduced to nearly $1 / 3$ to its previous level (Figure 8);

- No resonance like phenomenon was observed in any testing /operational regime.

\section{Conclusions}

1) Experimental modal analysis of overhang structures and subsequent operational runs of generator indicated global resonance phenomenon as the most likely cause for sharp increase endwinding vibration levels. Further, 4-node/2-lobe mode shape obtained by modal analysis seemed to have aggravated vibration behavior, thus, de-

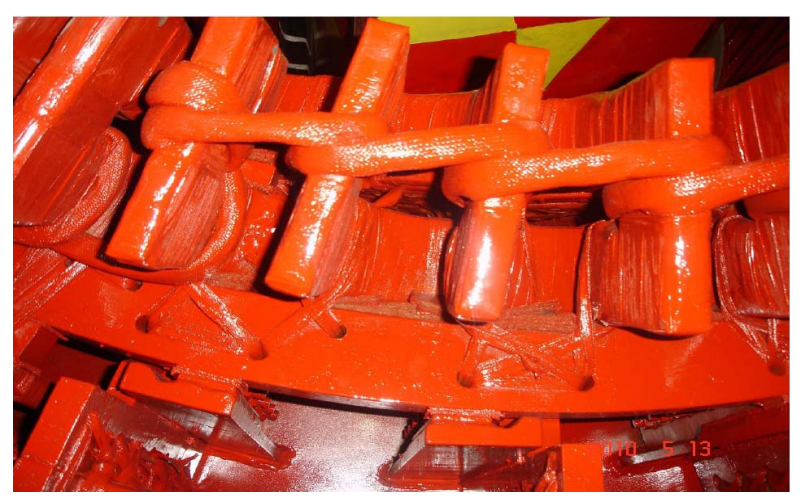

Figure 7. Rectification measure: a continuous resin rope integrating bar-head joints. 


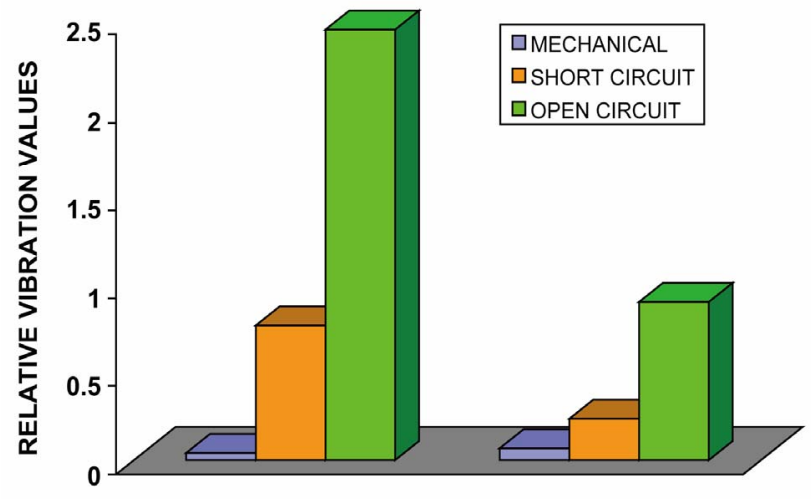

Figure 8. Endwinding vibration levels obtained before and after rectification.

monstrating its practical implication on overall structural dynamic response;

2) Appropriate rectification measures planned and implemented on overhangs and associated assembly had desired effect in arresting the endwinding vibration trend;

3) The complicated nature of both the forces and the responding structure make the exact relationship between cause and effect quite complex in various practical conditions including the present one. Hence, the study conducted and inferences drawn, do not claim to have comprehended all the aspects of endwinding vibration behaviour.

\section{References}

[1] K. Senske, S. Kulig, J. Hauhoff and D. Wünsch "Vibrational Behaviour of the Turbogenerator Stator End Winding in Case of Electrical Failures,” Conférence Internationale des Grands Rèseaux Electriques, Yokohama, 29 October 1997.

[2] D. Lambrecht and H. Berger "Integrated End-Winding Ring Support for Water-Cooled Stator Winding,” IEEE Transactions on Power Apparatus and Systems, Vol. PAS-102, No. 4, 1983, pp. 998-1006. doi:10.1109/TPAS.1983.317815

[3] L. Intichar, "Natural Frequency, Mode Shape Determination of Turbogenerator Overhangs," Symposium-Vibration Diagnostics on Power Plant Turbogenerators, Potsdam Sanssouci, 22-24 March 2006, pp. 371-391.

[4] E. D. Frerichs, "Monitoring of Endwinding Vibration of Generator with Fibre-Optics Accelerometers," Symposium-Vibration Diagnostics on Power Plant Turbogenerators, Sanssouci, 22-24 March 2006, pp. 373-428.

[5] R. Sewak, R. Ranjan and A. K. L. Rao, "Intricate Aspects of Turbogenerator Endwinding Vibration Monitoring Based on Data Analysis," International Conference on Condition Monitoring and Diagnosis, Beijing, 21-24 April 2008, pp. 130-135. doi:10.1109/CMD.2008.4580247

[6] D. Shally, M. Farrell and K. Sullivan, "Generator End Winding Vibration Monitoring,” 43rd International Universities Power Engineering Conference, Padova, 1-4 September 2008, pp. 1-5. doi:10.1109/UPEC.2008.4651488 